\title{
Molecular-level effects of eribulin and paclitaxel on breast cancer based on differential co-expression network analysis
}

\author{
J. Qin and Y.H. Chen \\ Department of Medicine, People's Hospital of Rizhao, Rizhao, China \\ Corresponding author: Y.H. Chen \\ E-mail: chenyanhuawen1@163.com
}

Genet. Mol. Res. 15 (2): gmr.15028192

Received August 8, 2015

Accepted November 26, 2015

Published July 15, 2016

DOI http://dx.doi.org/10.4238/gmr.15028192

\begin{abstract}
We investigated the effects of eribulin and paclitaxel on breast cancer (BC) by exploring molecular biomarkers and pathways. Co-expression networks were constructed by differentially coexpressed genes and links, and centralities were analyzed to explore the hub genes. Pathway-enrichment analysis was performed. The hub genes were validated using the polymerase chain reaction and western blotting. A total of 132 and 153 differentially expressed genes were identified in $\mathrm{BC}$ cell lines treated with eribulin and paclitaxel, respectively. Six hub genes were identified in two co-expression networks. The spliceosome pathway was the mutually significant pathway. The validation analysis was basically consistent with the bioinformatics. We successfully identified several hub genes and pathways relevant to the effects of eribulin and paclitaxel on $\mathrm{BC}$ based on the network analysis.
\end{abstract}

Key words: Breast cancer; Eribulin; Paclitaxel; Co-expression network; Hub genes; Pathway-enrichment analysis 


\section{INTRODUCTION}

Breast cancer (BC), the most frequently diagnosed carcinoma in females and the second leading cause of cancer death in women, is a heterogeneous disease with various pathological entities (Siegel et al., 2013). The rate of progression of BC depends on various factors, such as the histological type of the tumor, the woman's age, the hormonal conditions, the tumor microenvironment, the status of the receptors, and the genetic material (Reeder and Vogel, 2008). Despite the efficacy of many anti-cancer agents and the improved disease-free survival and overall survival of breast cancer patients, some patients still succumb to this disease (Jemal et al., 2011). Chemotherapy increases the 15 -year survival rate by $10 \%$ in women with breast cancer who are younger than 50; in older women, the increase is 3\% (EBCTCG, 2005). Despite new diagnostic and treatment options, roughly $30 \%$ of early-stage patients progress to metastatic disease (Dawood et al., 2010). Chemotherapy is predominantly used for cases of BC. Paclitaxel is a microtubule-stabilizing mediator medication that is used to treat a number of cancer types. It alters microtubule dynamics that are essential for maintaining cellular structure and play an important role in cellular functions, for example, the cell cycle (Sève and Dumontet, 2008; Perez, 2009). Eribulin (full name, eribulin mesylate; trade name, Halaven) was formally known as E7389 or ER-086526. It is also a microtubule-targeting modulator and has been used effectively to treat cancer (Towle et al., 2001). Currently, eribulin and paclitaxel are approved for the treatment of metastatic breast cancer (Martín, 2015; Mukai et al., 2015). However, the biological mechanisms underlying the chemotherapeutic effects of these drugs are still unclear.

Over the past decade, high-throughput technologies have brought unprecedented opportunities for the large-scale analysis of disease-related genes. They can be used to make sense of data and ascertain the key molecular mechanisms of biological phenomena. Complex diseases are usually characterized by diverse etiology, activation of multiple-signal transduction pathways, and various gene mutations. Network-based analysis has become an important and powerful approach to the elucidation of the biological implications underlying complex diseases (Baranzini et al., 2009; Sun et al., 2010; Jia et al., 2011).

We attempted to attain a system-wide understanding of the biological mechanisms underlying the curative effects of two drugs on BC. After screening the differentially expressed genes (DEGs) in the BC treatment groups (eribulin and paclitaxel) and the untreated BC subjects, we developed co-expression networks for BC treated with eribulin and paclitaxel by differentially co-expressed genes and links (DCGL). In addition, we explored the hub genes of these complex networks based on degree centrality analysis. Ultimately, the hub genes were validated in $\mathrm{BC}$ tissues treated with eribulin and paclitaxel using reverse-transcription polymerase chain reaction (RT-PCR) and western blotting. The study predicted the underlying molecular biomarkers relevant to the effects of eribulin and paclitaxel on breast cancer, which might reveal the mechanisms of eribulin and paclitaxel in $\mathrm{BC}$ treatment.

\section{MATERIAL AND METHODS}

\section{Data collection and preprocessing}

Based on the Affymetrix GeneChip Human Genome U133 Plus 2.0 [HG-U133 Plus_2] platform and the E-GEOD-50811 gene expression dataset (Dezső et al., 2014) 
untreated $\mathrm{BC}$ samples and treated $\mathrm{BC}$ cases were recruited from the ArrayExpress Archive of Functional Genomics Data (http://www.ebi.ac.uk/arrayexpress/). The ArrayExpress Archive is an international functional genomic database at the European Bioinformatics Institute (EMBL-EBI), and is recommended by most journals as a repository for data supporting peerreviewed publications (Kolesnikov et al., 2015). The E-GEOD-50811 gene expression dataset included 162 treated $\mathrm{BC}$ cases, comprising 81 eribulin-treated and 81 paclitaxel-treated $\mathrm{BC}$ cell lines, and 79 untreated cell lines, with three technical replicates as controls.

Before analysis, we conducted data preprocessing of the E-GEOD-50811 expression profile data using the expresso function in the Affy package (Gautier et al., 2004). To reduce the influence of nonspecific dataset factors, we performed background adjustment using the robust multichip average method (Ma et al., 2006) and data normalization using the quantilebased algorithm (Rifai and Ridker, 2001). PerfectMatch and mismatch match values were revised and selected using the MicroArray Suite 5.0 (MAS 5.0) algorithm (Pepper et al., 2007) and the median method, respectively. The AffyBatch data were converted to a gene expression dataset structure. The data were then screened using the featureFilter method of the genefilter package. Ultimately, each probe was mapped to one gene by getSYMBOL, where the probe is discarded if it does not match any genes.

\section{Detection of the DEGs}

To select key genes in the eribulin- or paclitaxel-treated BC cell lines, the DEGs in the untreated controls and treated BC cell lines were screened using the Significance Analysis of Microarrays (SAM) package, which correlates a large number of features (for example genes) with an outcome variable, such as a group indicator, quantitative variable, or survival time (Tibshirani et al., 2011). SAM assigns a score to each gene on the basis of a change in gene expression relative to the standard deviation of repeated measurements. Genes with scores greater than a threshold are deemed potentially significant. The percentage of such genes identified by chance is the false-discovery rate (FDR). The tables of thresholds, cutoff points, and the corresponding FDRs for SAM analysis were calculated using the functions of SAMR. compute.delta.table (Tusher et al., 2001). The significant gene table was computed starting with the samr object "samr.obj" and the delta.table object "delta.table" (Tusher et al., 2001).

The "relative difference" $d(i)$ in gene expression is:

$$
\mathrm{d}(i)=\frac{\bar{x}_{\mathrm{I}}(i)-\bar{x}_{\mathrm{U}}(i)}{\mathrm{s}(i)+\mathrm{s}_{0}}
$$

where $\overline{x_{\mathrm{I}}}(i)$ and $\overline{x_{\mathrm{U}}}(i)$ are defined as the average levels of expression for gene $(i)$ in states I and $\mathrm{U}$, respectively. The "gene-specific scatter" $s(i)$ is the standard deviation of repeated expression measurements. Genes were ranked to find significant changes in gene expression by the magnitude of their $d(i)$ values. To determine the number of falsely significant genes generated by SAM, horizontal cutoffs were defined as the smallest $d(i)$ among the genes and called significantly induced, and the least negative $d(i)$ among the genes were called significantly repressed. The number of falsely significant genes corresponding to each permutation was computed by counting the number of genes that exceeded the horizontal cutoffs for induced and repressed genes. The DEGs in eribulin- and paclitaxel-treated BC cell lines were selected based on delta value of 1.2745 and 1.2307 , respectively. 


\section{Construction of differential co-expression networks}

DCGL 2.0 (Yang et al., 2013) is an R package for identifying differentially co-expressed genes and links (DCGs and DCLs, respectively) from gene expression microarray data. It examines the expression correlation based on the exact co-expression changes of gene pairs between two conditions, and thus can distinguish between significant co-expression changes and relatively trivial ones (Yu et al., 2011). It has four functional modules: gene filtration, link filtration, differential coexpression analysis (DCEA), and differential regulation analysis. The differential co-expression profile (DCp) (Liu et al., 2010; Yu et al., 2011) and differential co-expression enrichment (DCe) (Liu et al., 2010; Yu et al., 2011) are involved in the DCEA module for extracting DCGs and DCLs.

DCp was used on the filtered set of gene co-expression value pairs. We measured differential co-expression $(\mathrm{dC})$ of the co-expression value pairs related to a particular gene using a length-normalized Euclidean distance. We then performed a permutation test to assess the significance of $\mathrm{dC}$, and a large number of permutation $\mathrm{dC}$ statistics formed an empirical null distribution. The $\mathrm{P}$ value for each gene could then be estimated.

DCe was also used to identify DCGs and DCLs based on the 'Limit Fold-Change' (LFC) model. First, we divided correlation pairs into three parts according to the pairing of signs of co-expression values and the multitude of co-expression values: pairs with the same signs, pairs with different signs, and pairs with differently signed high co-expression values. The first two parts were separately processed using the 'LFC' model to produce two subsets of DCLs, whereas the third part was directly added to the set of DCLs. The differential coexpression networks of eribulin- and paclitaxel-treated BC cell lines were determined from all the gene links. In our study, we defined the differential co-expression networks of eribulin and paclitaxel as network N1 and network N2, respectively.

\section{Centrality analysis}

To further identify key players in biological processes in the $\mathrm{BC}$ cell lines, we conducted a centrality analysis based on the number of nodes in the different networks (Scardoni and Laudanna, 2012). Centrality measures mainly comprise degree centrality, closeness centrality, and shortest path between centrality, in which the degree of the equivalent number of nodes directly adjacent to a given node $\mathrm{v}$ (indicating the degree the vertex) is the simplest topological index. Calculation of the degree allows the determination of the "degree distribution" $\mathrm{P}(\mathrm{k})$, which gives the probability that a selected node has exactly k links. Nodes with a high degree (highly connected) are called "hubs" and interact with several other genes, suggesting a central role in the interaction network. An obvious order of the vertices of a graph can be established by sorting them according to their degree (Koschützki and Schreiber, 2008). The degree $C(v)$ of a node $v$ was defined as:

$$
C(v)=\sum_{j} a_{v j}
$$

Genes with degrees $>20$ were defined as hub genes in this study.

\section{Pathway-enrichment analysis}

To further investigate the enriched pathways of the DEGs that were relevant to eribulin- 
or paclitaxel-treated $\mathrm{BC}$ cell lines, a pathway analysis was performed based on the Kyoto Encyclopedia of Genes and Genomes (KEGG) database (www.genome.jp/kegg/), which is widely used for the comprehensive inference pathway mapping of genes. We submitted the DEGs to the online tool of the Database for Annotation, Visualization and Integrated Discovery (Huang et al., 2009) (DAVID, http://david.abcc.ncifcrf.gov), and obtained all the pathways these genes enriched, using an empirical $\mathrm{P}$ value threshold of 0.01 .

\section{Validation of the hub genes}

\section{Materials}

We selected primary $\mathrm{BC}$ cell lines to perform our validation analysis. The control group comprised primary $\mathrm{BC}$ cell lines before treatment and the treatment groups comprised $\mathrm{BC}$ cell lines that had been successfully treated with drugs. We divided the treatment group into eribulin- and paclitaxel-treated groups.

\section{RT-PCR analysis}

Total RNA was used in first-strand synthesis with an oligo (dT18) primer, and was treated with $2 \mu \mathrm{L}$ RNasin $(40 \mu / \mu \mathrm{L}), 8.0 \mu \mathrm{L} 5 \mathrm{X}$ reverse transcriptase buffer, $8.0 \mu \mathrm{L}$ dNTPs, and $2 \mu \mathrm{L}$ AMV reverse transcriptase $(5 \mu / \mu \mathrm{L})$ according to the manufacturer instructions. The RT-PCR primer sequences for the hub genes in networks N1 and N2 are listed in Table 1. The PCR system comprised: $10 \mu \mathrm{L} 10 \mathrm{X}$ PCR buffer, $1 \mu \mathrm{L}$ Taq DNA polymerase, $3 \mu \mathrm{L}$ each forward and reverse primer, and $8 \mu \mathrm{L}$ dNTPs. The PCR conditions are given in Table 2 . Complementary DNA was used as a template, and $\beta$-actin was used as the internal reference. The experiment was repeated three times.

Table 1. Primer sequences and product lengths of the 12 hub genes in networks N1 and N2.

\begin{tabular}{|c|c|c|}
\hline Gene & Primer sequences $\left(5^{\prime}-3^{\prime}\right)$ & Length (bp) \\
\hline DUSP 8 & $\begin{array}{l}\text { F: TCATCTGCGAGAGCCGCTTCAT } \\
\text { R: AGCCAGACAGTGGACGATGACT }\end{array}$ & 140 \\
\hline FSTL3 & $\begin{array}{l}\text { F: ACATTGACACCGCCTGGTCCAA } \\
\text { R: ACTCCACGCCGTCGCACGAAT }\end{array}$ & 114 \\
\hline$T U B A 1 C$ & $\begin{array}{l}\text { F: CGGGCAGTGTTTGTAGACTTGG } \\
\text { R: CTCCTTGCCAATGGTGTAGTGC }\end{array}$ & 150 \\
\hline KLF6 & $\begin{array}{l}\text { F: AACCAGGCACTTCCGAAAGCAC } \\
\text { R: CTCAGAGGTGCCTCTTCATGTG }\end{array}$ & 113 \\
\hline$E I F 3 B$ & $\begin{array}{l}\text { F: ACAAGCAGCAGGCGAACACCAT } \\
\text { R: TCCACAAACGCTAAGGCACCGT }\end{array}$ & 97 \\
\hline UBR2 & $\begin{array}{l}\text { F: TCTTTCAGCAGACATTAGAACTGG } \\
\text { R: TCAGGAACCTGAGTTTGTGCGG }\end{array}$ & 115 \\
\hline KIF20A & $\begin{array}{l}\text { F: CAAGAGGCAGACTTTGCGGCTA } \\
\text { R: GCTCTGGTTCTTACGACCCACT }\end{array}$ & 130 \\
\hline PTPRK & $\begin{array}{l}\text { F: CACAGCCATCAATGTCACCACC } \\
\text { R: CACCTTTGGCTTGTGCTGGTCT }\end{array}$ & 128 \\
\hline ZSCAN2O & $\begin{array}{l}\text { F: CCTGGCAAACATGCTGAGAAGG } \\
\text { R: TCTGGTCCTTGCTCTTTCTCGG }\end{array}$ & 125 \\
\hline$D E P D C 1$ & $\begin{array}{l}\text { F: CTCGTAGAACTCCTAAAAGGCATG } \\
\text { R: CAACATCTTCCTGGCTTAGTTCTC }\end{array}$ & 129 \\
\hline$U N G$ & $\begin{array}{l}\text { F: CCACACCAAGTCTTCACCTGGA } \\
\text { R: CCGTGAGCTTGATTAGGTCCATG }\end{array}$ & 101 \\
\hline AURKA & $\begin{array}{l}\text { F: GCAACCAGTGTACCTCATCCTG } \\
\text { R: AAGTCTTCCAAAGCCCACTGCC }\end{array}$ & 158 \\
\hline$A C T B$ & $\begin{array}{l}\text { F: CTCCATCCTGGCCTCGCTGT } \\
\text { R: GCTGTCACCTTCACCGTTCC }\end{array}$ & 268 \\
\hline
\end{tabular}


Table 2. Polymerase chain reaction (PCR) amplification reaction conditions for the 12 hub genes.

\begin{tabular}{|c|c|}
\hline Gene & Reaction conditions \\
\hline DUSP8 & $94^{\circ} \mathrm{C} 5 \mathrm{~min} ; 35$ cycles of $94^{\circ} \mathrm{C} 30 \mathrm{~s}, 58^{\circ} \mathrm{C} 30 \mathrm{~s}, 72^{\circ} \mathrm{C} 40 \mathrm{~s} ; 72^{\circ} \mathrm{C} 10 \mathrm{~min}$ \\
\hline FSTL3 & $95^{\circ} \mathrm{C} 5 \mathrm{~min} ; 40$ cycles of $95^{\circ} \mathrm{C} 30 \mathrm{~s}, 60^{\circ} \mathrm{C} 30 \mathrm{~s}, 72^{\circ} \mathrm{C} 60 \mathrm{~s} ; 72^{\circ} \mathrm{C} 10 \mathrm{~min}$ \\
\hline TUBA1C & $95^{\circ} \mathrm{C} 2 \mathrm{~min} ; 40$ cycles of $95^{\circ} \mathrm{C} 15 \mathrm{~s}, 60^{\circ} \mathrm{C} 40 \mathrm{~s}, 72^{\circ} \mathrm{C} 20 \mathrm{~s} ; 72^{\circ} \mathrm{C} 10 \mathrm{~min}$ \\
\hline KLF6 & $94^{\circ} \mathrm{C} 2 \mathrm{~min} ; 45$ cycles of $95^{\circ} \mathrm{C} 10 \mathrm{~s}, 55^{\circ} \mathrm{C} 15 \mathrm{~s}, 72^{\circ} \mathrm{C} 10 \mathrm{~s} ; 72^{\circ} \mathrm{C} 10 \mathrm{~min}$ \\
\hline$E I F 3 B$ & $95^{\circ} \mathrm{C} 5 \mathrm{~min} ; 45$ cycles of $95^{\circ} \mathrm{C} 10 \mathrm{~s}, 62^{\circ} \mathrm{C} 20 \mathrm{~s}, 72^{\circ} \mathrm{C} 15 \mathrm{~s} ; 72^{\circ} \mathrm{C} 10 \mathrm{~min}$ \\
\hline$U B R 2$ & $94^{\circ} \mathrm{C} 2 \mathrm{~min} ; 40$ cycles of $95^{\circ} \mathrm{C} 10 \mathrm{~s}, 60^{\circ} \mathrm{C} 30 \mathrm{~s}, 60^{\circ} \mathrm{C} 30 \mathrm{~s} ; 72^{\circ} \mathrm{C} 10 \mathrm{~min}$ \\
\hline KIF20A & $95^{\circ} \mathrm{C} 10 \mathrm{~min} ; 40$ cycles of $95^{\circ} \mathrm{C} 15 \mathrm{~s}, 60^{\circ} \mathrm{C} 30 \mathrm{~s}, 72^{\circ} \mathrm{C} 10 \mathrm{~s} ; 72^{\circ} \mathrm{C} 10 \mathrm{~min}$ \\
\hline PTPRK & $95^{\circ} \mathrm{C} 10 \mathrm{~min} ; 40$ cycles of $95^{\circ} \mathrm{C} 15 \mathrm{~s}, 62^{\circ} \mathrm{C} 60 \mathrm{~s} ; 72^{\circ} \mathrm{C} 10 \mathrm{~min}$ \\
\hline ZSCAN20 & $94^{\circ} \mathrm{C} 10 \mathrm{~min} ; 35$ cycles of $94^{\circ} \mathrm{C} 15 \mathrm{~s}, 60^{\circ} \mathrm{C} 20 \mathrm{~s}, 72^{\circ} \mathrm{C} 10 \mathrm{~s} ; 72^{\circ} \mathrm{C} 10 \mathrm{~min}$ \\
\hline$D E P D C 1$ & $95^{\circ} \mathrm{C} 5 \mathrm{~min} ; 40$ cycles of $95^{\circ} \mathrm{C} 10 \mathrm{~s}, 60^{\circ} \mathrm{C} 30 \mathrm{~s}, 72^{\circ} \mathrm{C} 15 \mathrm{~s} ; 72^{\circ} \mathrm{C} 10 \mathrm{~min}$ \\
\hline$U N G$ & $95^{\circ} \mathrm{C} 10 \mathrm{~min} ; 40$ cycles of $95^{\circ} \mathrm{C} 15 \mathrm{~s}, 60^{\circ} \mathrm{C} 60 \mathrm{~s} ; 72^{\circ} \mathrm{C} 10 \mathrm{~min}$ \\
\hline AURKA & $95^{\circ} \mathrm{C} 5 \mathrm{~min} ; 35$ cycles of $95^{\circ} \mathrm{C} 30 \mathrm{~s}, 60^{\circ} \mathrm{C} 30 \mathrm{~s}, 72^{\circ} \mathrm{C} 40 \mathrm{~s} ; 72^{\circ} \mathrm{C} 7 \mathrm{~min}$ \\
\hline$A C T B$ & $95^{\circ} \mathrm{C} 2 \mathrm{~min} ; 40$ cycles of $94^{\circ} \mathrm{C} 30 \mathrm{~s}, 58^{\circ} \mathrm{C} 30 \mathrm{~s}, 72^{\circ} \mathrm{C} 30 \mathrm{~s} ; 72^{\circ} \mathrm{C} 10 \mathrm{~min}$ \\
\hline
\end{tabular}

\section{Western blotting}

Sodium dodecyl sulfate polyacrylamide gel electrophoresis (12\%) was conducted using $10 \mu \mathrm{g}$ protein, and the protein was electrotransferred $\left(4^{\circ} \mathrm{C}, 300 \mathrm{~mA}, 2 \mathrm{~h}\right)$ to a nitrocellulose membrane (NC). The NC membrane was then sealed with TBST (a mixture of Tris-buffered saline and Tween 20) containing $5 \%$ skimmed milk powder at $37^{\circ} \mathrm{C}$ for $2 \mathrm{~h}$. Rabbit antihuman antibody (diluted by 1:10,000 blocking solution) was applied to the NC membrane and incubated at $37^{\circ} \mathrm{C}$ for $2 \mathrm{~h}$. Unbound antibody was washed away with TBST (three times), and horseradish peroxidase-labeled sheep anti-rabbit IgG secondary antibody (1:5000) was incubated with the $\mathrm{NC}$ again at $37^{\circ} \mathrm{C}$ for $2 \mathrm{~h}$. After flushing with TBST, the substrate was applied to the NC for $3 \mathrm{~min}$ and exposed in the dark. The experiment was repeated ten times.

\section{Statistical analysis}

The products of the PCR experiment were analyzed by $1.5 \%$ agarose gel electrophoresis and the Quantity One gel imaging software (Bio-Rad, Hercules, CA, USA), and the results are reported as the content of the purpose gene relative to the $\beta$-actin bands. Analysis of the gray values from the western blotting experiment target bands was conducted using the ImageJ software (Invitrogen, Carlsbad, CA, USA), and the results are reported as the content of the purpose protein relative to the glyceraldehyde 3-phosphate dehydrogenase bands.

\section{RESULTS}

\section{Detection of DEGs}

A total of 241 samples associated with $\mathrm{BC}$ from the dataset were preprocessed to identify DEGs using the SAM package. Finally, 132 eribulin-treated and 153 paclitaxeltreated DEGs were identified in the treated $\mathrm{BC}$ cell lines.

\section{Construction of differential co-expression networks and centrality analysis}

The differential co-expression network N1 comprised 132 nodes and 216 edges (Figure 1), and N2 comprised 153 nodes and 212 edges (Figure 2). 


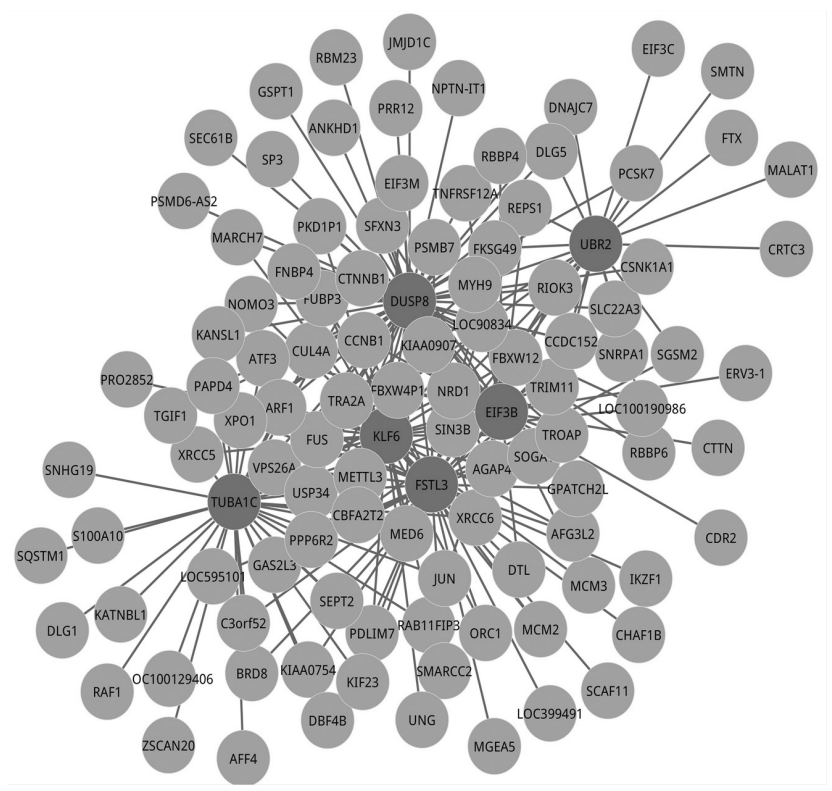

Figure 1. Differential co-expression networks of breast cancer cell lines treated with eribulin based on 132 differentially expressed genes. There were 132 nodes and 216 edges in the co-expression network; nodes refer to genes and edges between nodes indicate the interactions between genes in the network. The six hub genes are represented in dark gray.

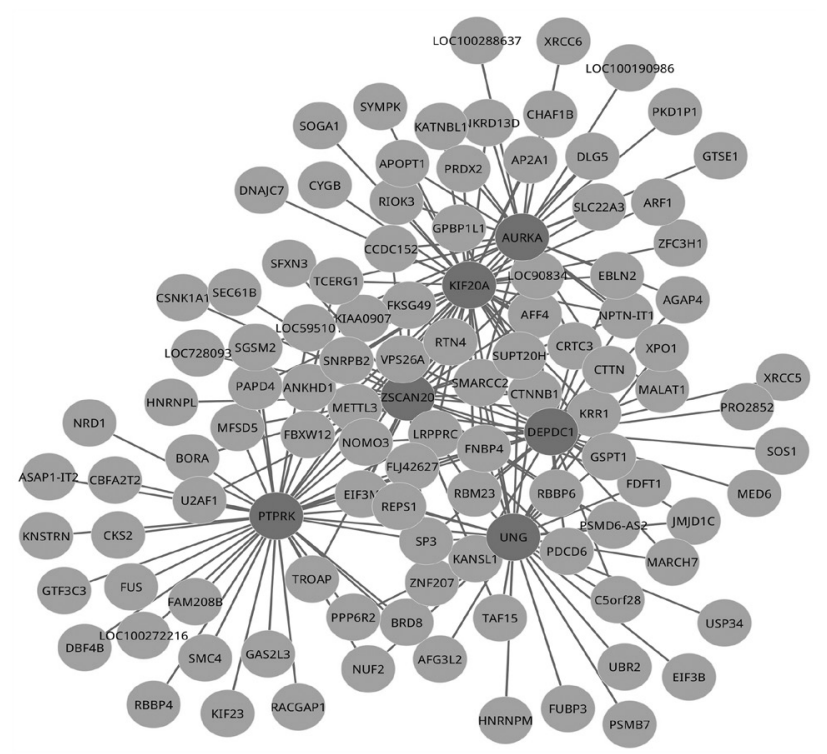

Figure 2. Differential co-expression networks of breast cancer cell lines treated with paclitaxel based on 153 differentially expressed genes. There were 153 nodes and 212 edges in the co-expression network; nodes refer to genes and edges between nodes indicate interactions between genes in the network. The six hub genes are represented in dark gray. 
By accessing degree centrality analysis under the threshold value degree $>20$ in descending order, we obtained six hub genes in co-expression networks N1 and network N2. There was no similarity between the hub genes in networks N1 and N2. The results are shown in Table 3.

Table 3. Hub genes of networks N1 and N2.
\begin{tabular}{l|c|l|c}
\hline \multicolumn{2}{|c|}{ Network N1 } & & Network N2 \\
\hline Genes & Degree & Genes & Degree \\
\hline DUSP8 & 58 & KIF20A & 45 \\
\hline FSTL3 & 42 & PTPRK & 41 \\
\hline TUBAIC & 40 & ZSCAN20 & 36 \\
\hline KLF6 & 34 & DEPDCl & 33 \\
\hline EIF3B & 27 & UNG & 32 \\
\hline$U B R 2$ & 22 & AURKA & 28 \\
\hline
\end{tabular}

\section{Pathway-enrichment analysis}

Pathway analysis based on the KEGG database showed that the DEGs in the BC cell lines treated with eribulin were significantly enriched in three terms: pathogenic Escherichia coli infection $(\mathrm{P}=0.0032)$, spliceosome $(\mathrm{P}=0.0041)$, and colorectal cancer $(\mathrm{P}=0.0096)$. The $\mathrm{DEGs}$ for the $\mathrm{BC}$ cell lines treated with paclitaxel were significantly enriched in spliceosome $(\mathrm{P}$ $=0.0075)$. Therefore, we conclude that the spliceosome pathway was the mutually significant term for the DEGs in the $\mathrm{BC}$ cell lines treated with eribulin or paclitaxel.

\section{Validation of the hub genes}

We verified the mRNA and protein expression levels of key genes (DUSP8, FSTL3, TUBA1C, KLF6, EIF3B, and UBR2 in network N1; and KIF20A, PTPRK, ZSCAN20, DEPDC1, $U N G$, and $A U R K A$ in network N2) using RT-PCR and western blotting. The results of the relative expression levels of the hub genes in N1 and N2 by RT-PCR and western blotting are shown in Figures 3 and 4, respectively.

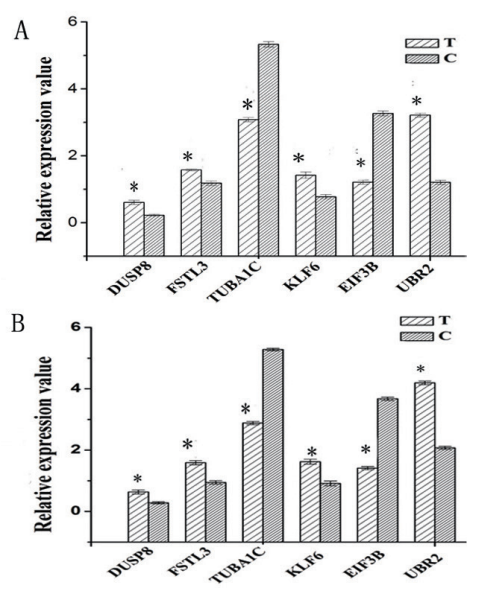

Figure 3. Relative expression of hub genes in breast cancer (BC) cell lines treated with eribulin. A. Polymerase chain reaction results and $\mathbf{B}$. results of western blotting analysis. T stands for the $\mathrm{BC}$ cell line samples treated with eribulin, and $\mathrm{C}$ represents the control samples. ${ }^{*} \mathrm{P}<0.05$. 


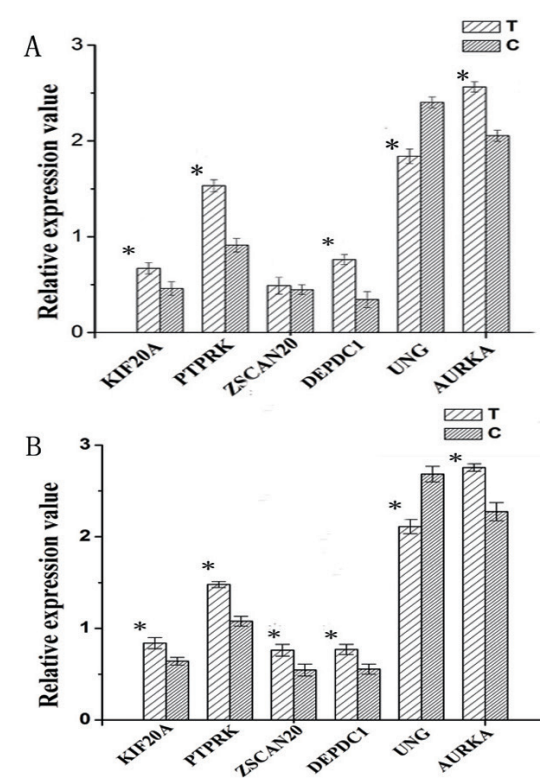

Figure 4. Relative expression of hub genes in breast cancer (BC) cell lines treated with paclitaxel. A. Polymerase chain reaction results and $\mathbf{B}$. results of western blotting analysis. T stands for the $\mathrm{BC}$ cell line samples treated with paclitaxel, and $\mathrm{C}$ represents the control samples. $* \mathrm{P}<0.05$.

We found that all the hub genes in N1 and N2 were significantly differentially expressed in the $\mathrm{BC}$ cell lines that had been treated with eribulin and paclitaxel, relative to the control group $(\mathrm{P}<0.05)$, except for ZSCAN20 in network N2 $(\mathrm{P}>0.05)$. The proteins corresponding to all the hub genes in N1 and N2 were significantly differentially expressed between the eribulin- or paclitaxel-treated $\mathrm{BC}$ cell lines relative to the controls $(\mathrm{P}<0.05)$. In addition, we noticed that the relative expression levels of DUSP8, FSTL3, KLF6, and UBR2 were upregulated, and the relative expression level of TUBA1C was downregulated in N1, which was consistent with the bioinformatic results, while the relative expression level of $E I F 3 B$ contradicted the bioinformatics in the eribulin-treated BC cell lines. In the $\mathrm{N} 2$ network, KIF20A, PTPRK, DEPDC1, and AURKA were upregulated, and $U N G$ was downregulated, which was consistent with the bioinformatic results, while the relative gene expression level of ZSCAN20 was not consistent with the bioinformatics.

\section{DISCUSSION}

We selected key genes in eribulin- or paclitaxel-treated BC cell lines and screened the DEGs in the untreated controls and treated cases using the SAM package. We then constructed differential co-expression networks for eribulin and paclitaxel as network N1 and network $\mathrm{N} 2$, respectively. To further identify hub genes and pathways for $\mathrm{BC}$ in biological processes, we used centrality analysis based on the node degrees in networks N1 and N2 and pathwayenrichment analysis based on the KEGG database. We identified several molecular biomarkers and relevant pathways in networks N1 and N2. Finally, we validated the hub genes; the results were consistent with the bioinformatic results. 
Based on the centrality analysis for the co-expression networks $\mathrm{N} 1$ and $\mathrm{N} 2$, we identified six hub genes in both N1 and N2 (DUSP8, FSTL3, TUBA1C, KLF6, EIF3B, and UBR2 in network N1; and KIF20A, PTPRK, ZSCAN20, DEPDC1, UNG, and AURKA in network N2). DUSP8 and KIF20A in particular had the highest degrees in N1 and N2, respectively, which may be important for BC therapy. DUSP is a phosphatase that can act upon tyrosine or serine/ threonine residues; it is well documented that DUSP8 promotes hypermethylation (Lim et al., 2007). Several observations suggest that DUSP8 affects the activation of the mitogenactivated protein kinase pathway in pancreatic cancer (Furukawa, 2015), and it serves as novel therapeutic targets for hepatocellular carcinoma (Fan et al., 2009). Additionally, it has been reported that the identification of candidate causal single nucleotide polymorphisms and genome-wide association study data have identified the candidate gene DUSP8 that might contribute to BC susceptibility (Lee et al., 2014a). In humans, the kinesin-like protein KIF20A is encoded by the KIF20A gene. It has been reported that KIF20A is related to the emergence of several types of cancer. It is a novel and promising candidate target for immunotherapeutic anti-cancer pancreatic cancer therapy (Imai et al., 2011), and it may be a potential molecular target for drug intervention in gastric cancer (Yan et al., 2012) and prostate cancer (Waltering et al., 2009). In this study, we postulated that KIF20A may be a molecular biomarker that influences breast cancer paclitaxel resistance. Moreover, the result was consistent with the research by Khongkow et al. (2015).

Pathway analysis showed that the functional pathways were inconsistent between the two groups. There were three enriched terms for the eribulin-treated $\mathrm{BC}$ cell lines and one enriched term for the paclitaxel-treated $\mathrm{BC}$ cell lines $(\mathrm{P} \leq 0.01)$. We noticed that the spliceosome pathway was the mutually significant term. A spliceosome is a large and complex molecular machine found primarily within the splicing speckles of the cell nucleus of eukaryotic cells. The spliceosome is assembled from RNAs and protein complexes. Alterations in the expression of a spliceosome protein can impact both specific splicing events and tumor cell motility in BC (Lee et al., 2008). Lee et al. (2014b) have suggested that splicing regulator interactions can suppress the metastatic progression of $\mathrm{BC}$ by altering the transcriptome. What is more, the spliceosome has been identified as an attractive therapeutic target in cancer therapy (Quidville et al., 2013).

In conclusion, our results identified several hub genes and pathways associated with the treatment of BC. Moreover, the validation results of most of the hub genes were consistent with the bioinformatic results. Therefore, those genes might be underlying biomarkers for eribulin and paclitaxel treatment associated with BC. Further validation and studies are needed to elucidate the effects of eribulin and paclitaxel on BC.

\section{Conflicts of interest}

The authors declare no conflict of interest.

\section{REFERENCES}

Baranzini SE, Galwey NW, Wang J, Khankhanian P, et al.; GeneMSA Consortium (2009). Pathway and network-based analysis of genome-wide association studies in multiple sclerosis. Hum. Mol. Genet. 18: 2078-2090. http://dx.doi. org $/ 10.1093 / \mathrm{hmg} / \mathrm{ddp} 120$

Dawood S, Broglio K, Ensor J, Hortobagyi GN, et al. (2010). Survival differences among women with de novo stage IV and relapsed breast cancer. Ann. Oncol. 21: 2169-2174. http://dx.doi.org/10.1093/annonc/mdq220 
Dezső Z, Oestreicher J, Weaver A, Santiago S, et al. (2014). Gene expression profiling reveals epithelial mesenchymal transition (EMT) genes can selectively differentiate eribulin sensitive breast cancer cells. PLoS One 9: e106131. http://dx.doi.org/10.1371/journal.pone.0106131

Early Breast Cancer Trialists' Collaborative Group (EBCTCG) (2005). Effects of chemotherapy and hormonal therapy for early breast cancer on recurrence and 15-year survival: an overview of the randomised trials. Lancet 365: 1687-1717. http://dx.doi.org/10.1016/S0140-6736(05)66544-0

Fan HH, Yu SL, Ou DL, Shen YC, et al. (2009). Abstract A241: searching for extracellular signal-regulated kinase (ERK)independent molecular targets of sorafenib in hepatocellular carcinoma (HCC). Mol. Cancer Ther. 8: A241. http:// dx.doi.org/10.1158/1535-7163.TARG-09-A241

Furukawa T (2015). Impacts of activation of the mitogen-activated protein kinase pathway in pancreatic cancer. Front. Oncol. 5: 23. http://dx.doi.org/10.3389/fonc.2015.00023

Gautier L, Cope L, Bolstad BM and Irizarry RA (2004). Affy - analysis of Affymetrix GeneChip data at the probe level. Bioinformatics 20: 307-315. http://dx.doi.org/10.1093/bioinformatics/btg405

Huang W, Sherman BT and Lempicki RA (2009). Systematic and integrative analysis of large gene lists using DAVID bioinformatics resources. Nat. Protoc. 4: 44-57. http://dx.doi.org/10.1038/nprot.2008.211

Imai K, Hirata S, Irie A, Senju S, et al. (2011). Identification of HLA-A2-restricted CTL epitopes of a novel tumourassociated antigen, KIF20A, overexpressed in pancreatic cancer. Br. J. Cancer 104: 300-307. http://dx.doi. org $/ 10.1038 /$ sj.bjc. 6606052

Jemal A, Bray F, Center MM, Ferlay J, et al. (2011). Global cancer statistics. CA Cancer J. Clin. 61: 69-90. http://dx.doi. org/10.3322/caac.20107

Jia P, Kao CF, Kuo PH and Zhao Z (2011). A comprehensive network and pathway analysis of candidate genes in major depressive disorder. BMC Syst. Biol. 5 (Suppl 3): S12. http://dx.doi.org/10.1186/1752-0509-5-S3-S12

Khongkow P, Gomes AR, Gong C, Man EP, et al. (2015). Paclitaxel targets FOXM1 to regulate KIF20A in mitotic catastrophe and breast cancer paclitaxel resistance. Oncogene 10.1038/onc.2015.152.

Kolesnikov N, Hastings E, Keays M, Melnichuk O, et al. (2015). ArrayExpress update--simplifying data submissions. Nucleic Acids Res. 43: D1113-D1116. http://dx.doi.org/10.1093/nar/gku1057

Koschützki D and Schreiber F (2008). Centrality analysis methods for biological networks and their application to gene regulatory networks. Gene Regul. Syst. Bio. 2: 193-201.

Lee JH, Horak CE, Khanna C, Meng Z, et al. (2008). Alterations in Gemin5 expression contribute to alternative mRNA splicing patterns and tumor cell motility. Cancer Res. 68: 639-644. http://dx.doi.org/10.1158/0008-5472.CAN-07$\underline{2632}$

Lee M, Dworkin AM, Gildea D, Trivedi NS, et al.; NISC Comparative Sequencing Program (2014a). RRP1B is a metastasis modifier that regulates the expression of alternative mRNA isoforms through interactions with SRSF1. Oncogene 33: 1818-1827. http://dx.doi.org/10.1038/onc.2013.133

Lee YH, Kim JH and Song GG (2014b). Genome-wide pathway analysis of breast cancer. Tumour Biol. 35: 7699-7705. http://dx.doi.org/10.1007/s13277-014-2027-5

Lim S, Green JA, Wong H, VanderBurg ME, et al. (2007). DUSP7 and DUSP8 promoter hypermethylations: predictors of clinical outcomes in advanced epithelial ovarian carcinoma. ASCO Annual Meeting Proceedings. J. Clin. Oncol. 25: 5501.

Liu BH, Yu H, Tu K, Li C, et al. (2010). DCGL: an R package for identifying differentially coexpressed genes and links from gene expression microarray data. Bioinformatics 26: 2637-2638. http://dx.doi.org/10.1093/bioinformatics/btq471

Ma L, Robinson LN and Towle HC (2006). ChREBP*Mlx is the principal mediator of glucose-induced gene expression in the liver. J. Biol. Chem. 281: 28721-28730. http://dx.doi.org/10.1074/jbc.M601576200

Martín M (2015). nab-Paclitaxel dose and schedule in breast cancer. Breast Cancer Res. 17: 81. http://dx.doi.org/10.1186/ $\underline{\text { s13058-015-0587-y }}$

Mukai H, Saeki T, Shimada K, Naito Y, et al. (2015). Phase 1 combination study of eribulin mesylate with trastuzumab for advanced or recurrent human epidermal growth factor receptor 2 positive breast cancer. Invest. New Drugs 33 : 119-127. http://dx.doi.org/10.1007/s10637-014-0161-y

Pepper SD, Saunders EK, Edwards LE, Wilson CL, et al. (2007). The utility of MAS5 expression summary and detection call algorithms. BMC Bioinformatics 8: 273. http://dx.doi.org/10.1186/1471-2105-8-273

Perez EA (2009). Microtubule inhibitors: Differentiating tubulin-inhibiting agents based on mechanisms of action, clinical activity, and resistance. Mol. Cancer Ther. 8: 2086-2095. http://dx.doi.org/10.1158/1535-7163.MCT-09-0366

Quidville V, Alsafadi S, Goubar A, Commo F, et al. (2013). Targeting the deregulated spliceosome core machinery in cancer cells triggers mTOR blockade and autophagy. Cancer Res. 73: 2247-2258. http://dx.doi.org/10.1158/00085472.CAN-12-2501 
Reeder JG and Vogel VG (2008). Breast cancer prevention. Cancer Treat. Res. 141: 149-164. http://dx.doi.org/10.1007/978$\underline{0-387-73161-2 \_10}$

Rifai N and Ridker PM (2001). Proposed cardiovascular risk assessment algorithm using high-sensitivity C-reactive protein and lipid screening. Clin. Chem. 47: 28-30.

Scardoni G and Laudanna C (2012). Centralities based analysis of complex networks. In: New Frontiers in Graph Theory (Yagang Zhang, eds.), InTech Open Access Publisher. http://www.intechopen.com/books/new-frontiers-in-graphtheory/centralities-based-analysis-of-networks. Accessed January 27, 2016.

Sève P and Dumontet C (2008). Is class III beta-tubulin a predictive factor in patients receiving tubulin-binding agents? Lancet Oncol. 9: 168-175. http://dx.doi.org/10.1016/S1470-2045(08)70029-9

Siegel R, Naishadham D and Jemal A (2013). Cancer statistics, 2013. CA Cancer J. Clin. 63: 11-30. http://dx.doi. org $/ 10.3322 /$ caac. 21166

Sun J, Jia P, Fanous AH, van den Oord E, et al. (2010). Schizophrenia gene networks and pathways and their applications for novel candidate gene selection. PLoS One 5: e11351. http://dx.doi.org/10.1371/journal.pone.0011351

Tibshirani R, Chu G, Narasimhan B and Li J (2011). SAM: significance analysis of microarrays. R package version. 2. https://cran.r-project.org/web/packages/samr/samr.pdf. Accessed January 27, 2016.

Towle MJ, Salvato KA, Budrow J, Wels BF, et al. (2001). In vitro and in vivo anticancer activities of synthetic macrocyclic ketone analogues of halichondrin B. Cancer Res. 61: 1013-1021.

Tusher VG, Tibshirani R and Chu G (2001). Significance analysis of microarrays applied to the ionizing radiation response. Proc. Natl. Acad. Sci. USA 98: 5116-5121. http://dx.doi.org/10.1073/pnas.091062498

Waltering KK, Helenius MA, Sahu B, Manni V, et al. (2009). Increased expression of androgen receptor sensitizes prostate cancer cells to low levels of androgens. Cancer Res. 69: 8141-8149. http://dx.doi.org/10.1158/0008-5472. CAN-09-0919

Yan GR, Zou FY, Dang BL, Zhang Y, et al. (2012). Genistein-induced mitotic arrest of gastric cancer cells by downregulating KIF20A, a proteomics study. Proteomics 12: 2391-2399. http://dx.doi.org/10.1002/pmic.201100652

Yang J, Yu H, Liu BH, Zhao Z, et al. (2013). DCGL v2.0: an R package for unveiling differential regulation from differential co-expression. PLoS One 8: e79729. http://dx.doi.org/10.1371/journal.pone.0079729

Yu H, Liu BH, Ye ZQ, Li C, et al. (2011). Link-based quantitative methods to identify differentially coexpressed genes and gene pairs. BMC Bioinformatics 12: 315. http://dx.doi.org/10.1186/1471-2105-12-315 